\section{GIS TOOL FOR SEMI-AUTOMATIC HAZARD ASSESSMENT OF EARTHQUAKE-TRIGGERED LANDSLIDES}

J.C. Román-Herrera ${ }^{1}$, M.J. Rodríguez-Peces ${ }^{1}$, J. Delgado², M. Tsige1

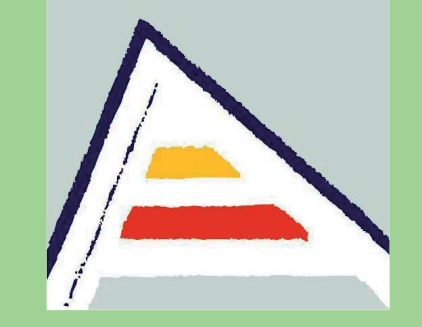

Universitat d'Alacan

Universidad de Alicante
UNIVERSIDAD

(2) Department of Environment and Earth Sciences, University of Alicante

\section{INTRODUCTION}

We are developing a new GIS code to analyze the risk of slope instabilities seismically induced to obtain maps that show the areas with the highest risk level. The semi-automatic program that we are writting in Phyton, uses ArcGIS software and feeds on geological-geotechnical data.The code consists in the implementation of the Newmark method at a local and regional scale, with the aim of obtaining Newmark's displacement maps and critical acceleration. For that purpose, we need to use an infinite slope limit equilibrium model by means of a geographic information system. It is important to emphasize that the code obtains safety factors and critical acceleration values for circular and non-circular fault surfaces based on different limit equilibrium methods, such as Bishop or Janbu and Morgenstern-Price. To feed the program, we need a large amount of empirical data that might be difficult to obtain for example the geological-geotechnical lithological classification. This data can be obtained from the standard pensifica(SPT) of cation (St the soweer, if there are rock substratewe need to know the resistance parameters present in the discontinuities of the rock. For example: cohesion or friction angle. On the other hand, you have to take into account the slope maps. These are essentia for instability. Depending mainly on the lithology, the hydrological conditions (dry or saturated) and other external factors (intensity level of the shaking soil during an earthquake). For that purpose, we are using geotechnical data from Lorca seismic event that happened in Murcia (Spain) on the 11th of May of 2011.

\section{ORIGIN OF THE DATA: SEISMIC EVENT IN LORCA (SPAIN)}

Lorca is located in the Alto Guadalentin region in the Southeast of the Iberian Peninsula. Lorca is located in the Bética Mountain Range, which is the most Western end of the Alpine belt (result of the separation of the Euroasians and African . plates). During the last $9-10$ million years it has continued to produce an in the crust but in a different tectonic regime. In this new framework is configured the current landscape of basins and mountains associated with the activity of the numerous faults that dip and raise blocks of bark, including the Alhama Fault of Murcia (FAM). On May 11th 2011, at 15:05 UTC there was a fatefu seismic event of $\mathrm{Mw}$ 4.5. This event was followed by a smal series of replicas with magnitudes lower than mbLg 2.5 (6 tremors) and a greater seismic event with a magnitude of Mw 5.1 at 16:47 UTC.
The two main events were located very close to each other, approximately on the North of FAM, $2 \mathrm{~km}$ Northwest of the city of Lorca. However, most of the replicas are concentrated on the Southeast of this area. The geological source of the earthquake FAM. FAM was first descr Bousquet et al (1979) and has been the subject of Bumerous (197) high seis worenic poct its active chan this seismogenic potential are evident. It is a sinistral tear fault with an inverse component that varies from one segment to another of the fault; the FAM extends along the NW edge of the Guadalentin depression, from the vicinity of Alcantarilla to the suroundings of Gónar in Almería, reaching a total length of at least 85 kilometers. The fault is segmented into several sections with different directions and internal structure of the variable complexity shear zone.

\section{METHODOLOGY: NEWMARK METHOD AND HIS APLICATION IN TO SCRIPT}

The selected method for the development of the semiautomatic tool is based on the Newmark methods (1965) Jibson et al. (2000) and Jibson (2007), which allows to predict the displacements originated in the natura slopes as a result of a seismic movement obtaining maps of rover gy begin gy begins analysing the stablity of the slopes from a static and aseismic point of view, which allow us to obtain the safety factor of a hillside in case of a landslide. Jibson et al. (2000) proposed this

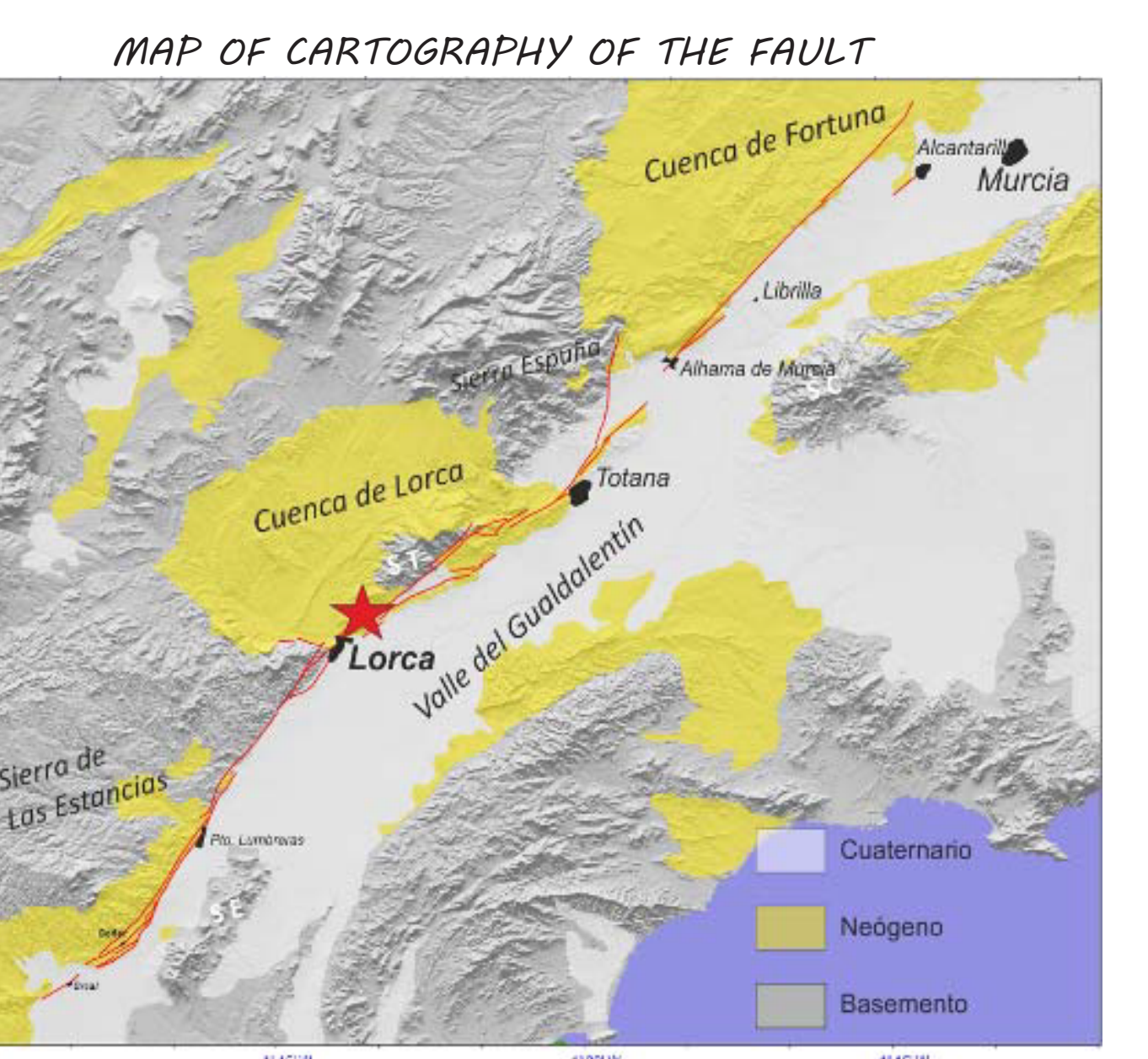

equation (1) based on the infinity slope.

To consider the dynamic effect of the earthquake, the critical acceleration is incorporated in the second phase of the analysis, which is defined as the minimum acceleration necessary to overcome shear resistance and initiate the displacement of the rigid block. Newmark (1965) defined that acceleration is inclined to the slope and it is a product of the safety factor and the angle of thrust, thus obtaining equation (2).
$a_{c}=(S F-1) g \tan \alpha$
$S F=\frac{c^{\prime}}{\gamma t \sin \alpha}+\frac{\tan \phi^{\prime}}{\tan \alpha}-\frac{m \gamma_{w} \tan \phi^{\prime}}{\gamma \tan \alpha}$
$\circ$ SF: Safety factor
$\circ c^{\prime}$ : Effective conesion
$\circ \phi$ : Effective friction
$\Phi^{\prime}:$ Effective friction $\quad$ ot : Normal depth of the failure surface
$\begin{array}{ll}m \text { : The degree of saturation of the failure surface } & \circ g: \text { Acceleration of the gravity } \\ \circ v_{y} \text { : Specific weight of water } & \circ y: \text { Specific weight of slope material }\end{array}$

The displacement of a slip can be calculated in an empirical way using regression equations based in turn on the parameters of the earthquake (magnitud and epicentral distance) and / or simple strong ground motion parameters, as shown in equation (3).

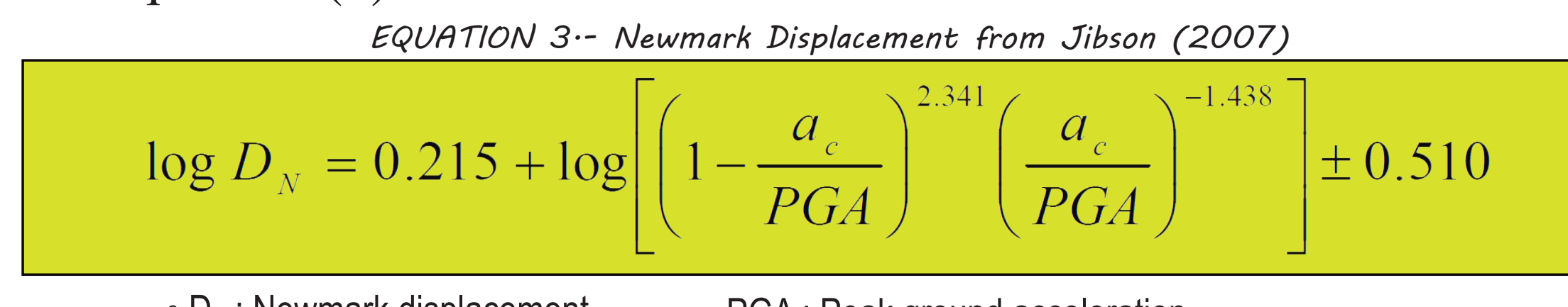

$D_{N}$ : Newmark displacement $\quad$ PGA: Peak ground acceleration
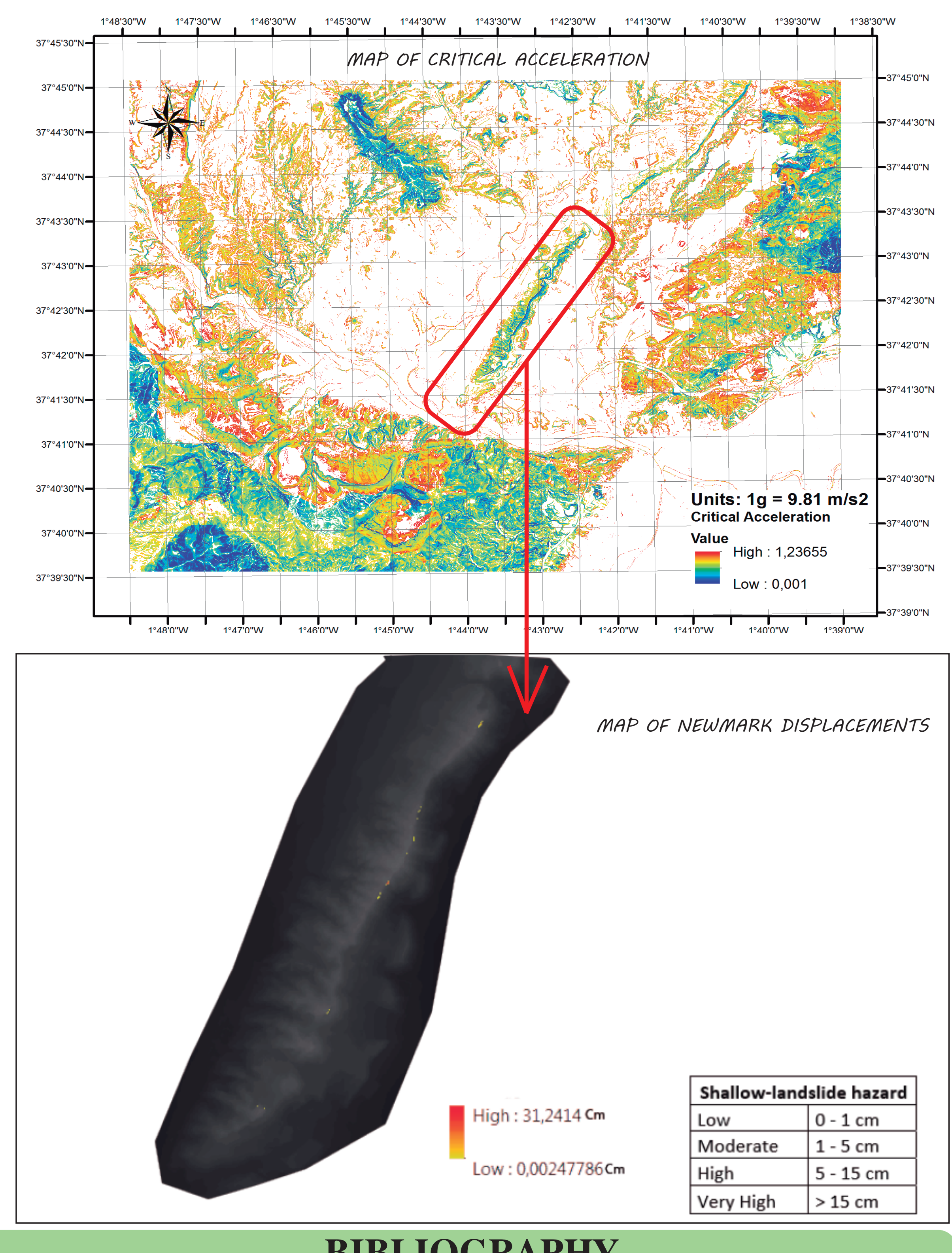

BIBLIOGRAPHY

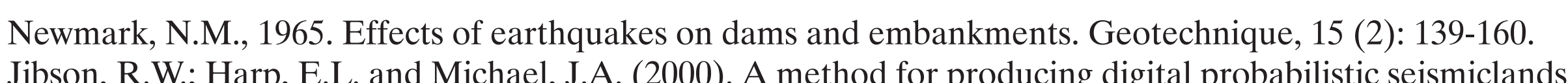
de hazard maps. Engineering Geology, 58: $271-289$.
- isbon, R.W. (2007). Regression models for estimating coseismic landslide displacement. Engineering Geology,
91 : 209-218.
- Rodrigue-Peces, M.J., (2010). Analysis of earthquake-triggered landslides in the South of Iberia: Testing the Rodríguez-Peces, M.J., (2010). Analysis of earthquake-triggered landslides in the South of Iberia: Testing
use of the Newmark's method at different scales.
- IGME-UCM (2011). JJ. Martínez Díaz; M.Á. Rodríguez-Pascua; R. Pérez López; J. García Mayordomo; J.L

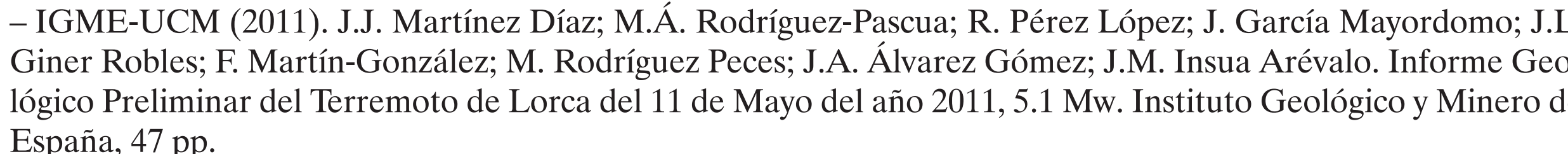

